\title{
Pups of Dams Fed Low-Fat Diet during Pregnancy and Lactation Showed Strong Preference for High-Fat Diet to Achieve Optimal Growth
}

\author{
Yoko NAKASHIMA and Akie SATO \\ Department of Human Nutrition, Seitoku University, 550 Iwase, Matsudo, Chiba 271-8555, Japan
}

(Received March 25, 2011)

\begin{abstract}
Summary To investigate the causes why pups of dams fed a low-fat high-carbohydrate diet (LFD) showed a strong preference for fat, three groups of dams were fed one of three diets during pregnancy and lactation: the LFD, a control diet (CTD) or a high-fat low-carbohydrate diet (HFD). After weaning, pups of each of the three groups were divided into two equal subgroups (Pair 1 and Pair 2), for a total of six pup subgroups. Each subgroup was placed on a two-choice diet program of the LFD and the HFD (Pair 1), or the LFD and a HFDLE (with cellulose added to maintain the same energy concentration as the LFD) (Pair 2 ), for $3 \mathrm{wk}$. Although the energy intake of dams fed the LFD during the nursing period was lower than that of the HFD group, no significant difference in body weight was observed among the three groups. At weaning, the body weight of pups nursed by dams fed the LFD was lower than that of the other groups. In Pair 1, the HFD intake ratio of the LFD and the HFD groups during the self-selection period was higher than that of the CTD group. In Pair 2, the HFDLE intake ratio of the LFD and the CTD groups was lower than that of the HFD group. At the end of the self-selection period, no significant difference in body weight was observed among the three groups of Pair 1. However, in Pair 2, the body weight of the LFD group was lower than that of the other groups. Therefore, it was supposed that pups of dams fed the LFD showed strong preference for the HFD containing high energy in order to achieve optimal growth.
\end{abstract}

Key Words parental nutrition, self-selection, fat-feeding, weaning pups

Nutritional conditions during pregnancy and lactation have a major role in the metabolic and hormonal interactions between the maternal body, the fetus and the suckling pup. Fetus and suckling pup growth is influenced by maternal nutritional conditions (1). Lipids are considered to be important as an energy-dense nutrient and as a source for essential fatty acids. Lipids play a functional role in fetal and suckling-pup development (2). Although the physiological factors contributing to fat diet self-selection are unknown, physiological hormones are maintained through a complex nutrient metabolic pathway regulated by hormones and the central nervous system (3-5).

Insulin and leptin are of particular importance in the long-term control of food intake and energy homeostasis (6). Insulin is the controller of blood glucose levels and is secreted by $\beta$ cells of the pancreas as controlled by glucose levels (7). Although glucose homeostasis may remain normal, both fasting and postprandial insulin concentrations tend to increase with age (8). Leptin is produced by adipose tissue and has potent effects on body weight, food intake regulation and energy consumption through its receptors in the hypothalamus (9). Vickers et al. suggested that prenatal exposure to maternal malnutrition leads to changes in the regula-

E-mail: yokon@seitoku.ac.jp tion of the insulin-leptin endocrine axes that appear to predispose offspring to diet-induced obesity $(10,11)$. It has also been shown that dietary fat quantity and quality affect plasma leptin concentrations in neonatal rats $(12,13)$. As this phenomenon takes place early in development, diets reducing insulinemia in early life may be beneficial to later life. It seems important to investigate the effect of dams' dietary fat type during pregnancy and lactation on spontaneous fat choice made by offspring and the relationship between their choice and plasma insulin and leptin concentration.

The large variations that exist in food choice, especially for fat preference, can be linked to animal strain, age, environment, genetic background, parental nutrition, feeding history and modifications of energy expenditure such as food deprivation and exercise (14-18). We are particularly interested in examining whether dams' dietary fat types during pregnancy and lactation influence the preferential fat intake of their pups after weaning. We reported previously that three groups of dams were fed the low-fat high-carbohydrate diet (LFD), the control diet (CTD) or the high-fat low-carbohydrate diet (HFD) with added lard, during pregnancy and lactation, and when their pups were placed on a twochoice diet program consisting of the LFD and the HFD after weaning, the HFD intake ratio [HFD intake (g)/ total intake (g)] for pups nursed by dams fed the LFD or 
the HFD was significantly higher than that for pups nursed by dams fed the CTD (17). We also reported previously that when three groups of pups nursed by dams fed the LFD, the CTD or the HFD were placed on a twochoice diet program consisting of a fat-protein diet (FPD) and a carbohydrate-protein diet (CPD) after weaning, the FPD intake ratio [FPD intake $(\mathrm{g}) /$ total intake $(\mathrm{g})$ ] for pups nursed by dams fed the LFD was significantly higher than that for pups nursed by dams fed the CTD and the HFD. As the fat energy ratio (F ratio) of pups nursed by dams fed the LFD was higher than that of AIN-93G (19), it was assumed that the fat preference of pups nursed by dams fed the LFD is strong and not conditioned by the type of diet consumed by their dam.

Although the effect of maternal macronutrients on chronic disease in the offspring has been the topic of many studies, the precise causes are poorly understood. Thus, the purpose of this study is to clarify why the preferential fat intake of pups nursed by dams fed the LFD is stronger than that of pups nursed by dams fed the CTD or the HFD. The fat content and the energy density (kcal/g) of the HFD are higher than that of the LFD. We were particularly interested in examining whether pups nursed by dams fed the LFD would show strong preference for the fat or energy density of the HFD after weaning. In order to clarify we compared preference for the HFD and the HFDLE (with cellulose added to maintain the same energy concentration as the LFD) in pups nursed by dams fed the LFD. The pups were placed on a two-choice diet program consisting of the LFD and the HFD, and the LFD and the HFDLE after weaning. Body and fat tissue weights and plasma lipid and hormone concentrations were also measured and analyzed in relation to their regimen and their observed dietary preference.

\section{METHODS}

Animals and diets. Sperm-positive pregnant rats of Sprague-Dawley strain on day 3 of pregnancy (10 wkold) were commercially obtained from CLEA Japan, Inc. (Tokyo, Japan). They were housed individually in plastic cages with paper chip (ALPHA-DriTM, Shepherd Specialty Papers, Inc., Michigan) bedding. They were maintained in a room kept at a constant temperature $\left(23 \pm 1^{\circ} \mathrm{C}\right)$ and illuminated with a 12-h light/12-h dark cycle with lights on at 7:00 a.m. They had free access to food and water. They were weighed and food intake was measured every day between 10:00 a.m. and noon to determine daily intake during the experimental period.

The composition of the diets is shown in Table 1 . The CTD was based on the AIN-93G diet (19). Basically, the amount of soybean-oil in the LFD was reduced to $1 / 2$ that in the CTD, and lard (14\%) was added to the HFD, substituting for cornstarch. The HFDLE was prepared by adding cellulose to the HFD to maintain the same metabolizable energy concentration as the LFD. Lard, soybean-oil and dietary components were obtained from the Oriental Yeast Co., Ltd. (Tokyo, Japan).

Experimental design. Twelve pregnant rats (on day 3 of pregnancy) were divided into three equal groups.
Table 1. Composition of the diets.

\begin{tabular}{lcccc}
\hline \multicolumn{1}{c}{ Ingredient } & LFD & CTD & HFD & HFDLE \\
\hline Casein & 20.0 & 20.0 & 20.0 & 16.2 \\
L-Cystine & 0.3 & 0.3 & 0.3 & 0.24 \\
Cornstarch & 56.45 & 52.9 & 38.95 & 28.06 \\
Sucrose & 10.0 & 10.0 & 10.0 & 8.1 \\
Soybean oil & 3.5 & 7.0 & 7.0 & 5.6 \\
Lard & - & - & 14.0 & 11.2 \\
Cellulose & 5.0 & 5.0 & 5.0 & 26.8 \\
Mineral mixture & 3.5 & 3.5 & 3.5 & 2.8 \\
Vitamin mixture & 1.0 & 1.0 & 1.0 & 0.8 \\
Choline bitartrate & 0.25 & 0.25 & 0.25 & 0.2 \\
tert-Butylhydroquinone & 0.0014 & 0.0014 & 0.0014 & 0.0014 \\
\hline Energy (kcal/g) & 3.5 & 3.8 & 4.6 & 3.5 \\
Fat energy ratio (\%) & 10.7 & 17.1 & 42.1 & 42.1 \\
Carbohydrate energy & 68.5 & 62.3 & 40.4 & 40.4 \\
$\quad$ ratio (\%) & & & & \\
Protein energy ratio & 20.8 & 20.6 & 17.5 & 17.5 \\
$\quad$ (\%) & & & & \\
\hline
\end{tabular}

The composition of all ingredients is given in grams per $100 \mathrm{~g}$ of diet.

The mineral mixture and the vitamin mixture were based on the AIN-93G formulation (19). HFDLE was prepared by adding cellulose to HFD to maintain the same metabolizable energy concentration as the LFD.

Each group received the LFD, the CTD or the HFD during pregnancy and lactation. Within $24 \mathrm{~h}$ of birth, litters were culled to 10 pups ( 5 males and 5 females) each and nursed by their dams for $21 \mathrm{~d}$. At weaning, two pups (male and female) each from the litters of all dams were killed by decapitation and their blood collected. Perirenal fat tissue was removed and weighed.

After weaning, the remaining pups were housed individually. Pups nursed by dams fed the LFD, the CTD and the HFD were divided into two groups of equal size. One group each of pups nursed by dams fed the LFD, the CTD and the HFD was placed on a two-choice diet program in which they self-selected from two food cups, each containing either the LFD or the HFD (Pair 1). The other groups were provided both the LFD and the HFDLE, placed in separate cups (Pair 2). Dietary ingestion of both diets and body weight were measured every day. On day 21 after weaning, the self-selecting rats were sacrificed by decapitation. Dams were sacrificed immediately after their pups were weaned. They were anesthetized and killed by cardiac puncture. Blood was collected with a heparinized syringe. After centrifugation $(3,000 \mathrm{rpm} \times 30)$, plasma was removed, frozen immediately and stored at $-80^{\circ} \mathrm{C}$. Perirenal fat tissues were removed from dams and pups and weighed.

The studies were performed in accordance with the Animal Experimentation Guidelines of the Laboratory Animal Care Committee of Seitoku University.

Analytical methods. Triacylglycerol (TG), total-cholesterol (T-cho), insulin and leptin concentrations in plasma were measured using test kits (TG: Triglyceride E-test Wako, T-cho: Cholesterol E-test Wako, insulin: 
Table 2. Food and energy intake by dams during pregnancy and lactation, and body and perirenal fat tissue weights and plasma lipid and hormone concentrations in dams at the end of lactation.

\begin{tabular}{|c|c|c|c|}
\hline Group & LFD & CTD & HFD \\
\hline \multicolumn{4}{|l|}{ Food intake (g) } \\
\hline Pregnant period & $379 \pm 22^{\mathrm{a}}$ & $368 \pm 14^{\mathrm{a}}$ & $305 \pm 35^{b}$ \\
\hline Nursing period & $877 \pm 55^{\mathrm{ab}}$ & $875 \pm 41^{\mathrm{a}}$ & $785 \pm 73^{b}$ \\
\hline \multicolumn{4}{|l|}{ Energy intake (kcal) } \\
\hline Pregnant period & $1,326 \pm 77$ & $1,399 \pm 52$ & $1,403 \pm 161$ \\
\hline Nursing period & $3,070 \pm 193^{\mathrm{a}}$ & $3,326 \pm 189^{\mathrm{ab}}$ & $3,611 \pm 336^{\mathrm{b}}$ \\
\hline \multicolumn{4}{|l|}{ Body weight gain (g) } \\
\hline Pregnant period & $148 \pm 23$ & $156 \pm 19$ & $158 \pm 34$ \\
\hline Nursing period & $-5 \pm 18$ & $-3 \pm 13$ & $9 \pm 18$ \\
\hline Final body weight (g) & $279 \pm 15$ & $286 \pm 13$ & $292 \pm 29$ \\
\hline $\begin{array}{l}\text { Perirenal fat tissue weight } \\
\text { (g/100 g body weight })\end{array}$ & $0.402 \pm 0.119$ & $0.364 \pm 0.96$ & $0.517 \pm 0.227$ \\
\hline \multicolumn{4}{|l|}{ Plasma concentration } \\
\hline Triacylglycerol (mg/dL) & $70.3 \pm 12.1$ & $52.6 \pm 8.9$ & $74.2 \pm 18.8$ \\
\hline Total-cholesterol (mg/dL) & $66.4 \pm 7.9$ & $58.7 \pm 4.6$ & $71.3 \pm 10.2$ \\
\hline Insulin $(\mathrm{ng} / \mathrm{mL})$ & $4.55 \pm 1.03^{\mathrm{a}}$ & $2.62 \pm 0.80^{\mathrm{a}}$ & $2.27 \pm 1.11^{\mathrm{a}}$ \\
\hline Leptin (ng/mL) & $3.36 \pm 0.78$ & $2.86 \pm 0.84$ & $3.92 \pm 1.02$ \\
\hline \multicolumn{4}{|c|}{$\begin{array}{l}\text { Values represent means } \pm \text { SD, } n=4 \text {. Within each row, values not sharing a common superscript letter are significantly differ- } \\
\text { ent at } p<0.05 \text {. } \\
\text { Pregnancy period: from day } 3 \text { of pregnancy to delivery (on day } 21 \text { of pregnancy). Nursing period: from delivery to weaning } \\
\text { (pups were weaned on day } 21 \text { of age). Body weight gain during pregnancy period: from day } 3 \text { of pregnancy to one day } \\
\text { before delivery (on day } 20 \text { of pregnancy). Body weight gain during nursing period: from delivery to weaning (pups were } \\
\text { weaned on day } 21 \text { of age). }\end{array}$} \\
\hline
\end{tabular}

Table 3. Body and perirenal fat tissue weights, and plasma lipid and hormone concentrations of 21-d-old pups nursed by dams fed the LFD, the CTD and the HFD.

\begin{tabular}{|c|c|c|c|}
\hline Group & LFD & CTD & HFD \\
\hline Body weight (g) & $52.2 \pm 1.5^{\mathrm{a}}$ & $57.9 \pm 2.9^{b}$ & $62.9 \pm 3.1^{b}$ \\
\hline $\begin{array}{l}\text { Perirenal fat tissue weight } \\
\text { (g/100 g body weight) }\end{array}$ & $0.266 \pm 0.093^{a}$ & $0.383 \pm 0.097^{\mathrm{ab}}$ & $0.495 \pm 0.125^{b}$ \\
\hline \multicolumn{4}{|l|}{ Plasma concentration } \\
\hline Triacylglycerol (mg/dL) & $106 \pm 27^{\mathrm{a}}$ & $152 \pm 18^{b}$ & $199 \pm 38^{c}$ \\
\hline Total-cholesterol (mg/dL) & $114 \pm 9$ & $122 \pm 13$ & $121 \pm 10$ \\
\hline Insulin $(\mathrm{ng} / \mathrm{mL})$ & $1.65 \pm 0.43^{\mathrm{a}}$ & $0.86 \pm 0.28^{b}$ & $0.86 \pm 0.32^{b}$ \\
\hline Leptin $(\mathrm{ng} / \mathrm{mL})$ & $0.93 \pm 0.076^{\mathrm{a}}$ & $1.16 \pm 0.17^{\mathrm{b}}$ & $1.85 \pm 0.34^{\mathrm{c}}$ \\
\hline
\end{tabular}

Values represent means $\pm \mathrm{SD}, n=8$. Within each row, values not sharing a common superscript letter are significantly different at $p<0.05$. The pups were weaned on day 21 of age.

Rat Insulin ELISA Kit, leptin: Rat Leptin ELISA Kit) (Wako Pure Chemical Industries, Ltd., Osaka, Japan).

Statistical analysis. Values are presented as individual group mean \pm SD. Comparison between groups was made by ANOVA (one-way ANOVA in Tables 2-5, and two-way ANOVA in Figs. 1 and 2). Differences in values between groups were tested utilizing Scheffe's multiplerange test. Differences were considered significant at $p<0.05$.

\section{RESULTS}

Food and energy intake by dams during pregnancy and lactation, and body and fat tissue weights, and plasma lipid and hormone concentrations in dams and their suckling pups

Food intake of dams fed the HFD during pregnancy was lower than that of dams fed the CTD and the LFD (Table 2) $(p<0.05)$. No significant difference in energy intake was observed among these three groups. Energy intake of dams fed the HFD during lactation was the highest and that by dams fed the LTD was the lowest among three groups $(p<0.05)$. No significant difference in body weight gain during the pregnancy and the nursing periods or final body weight was observed among these three groups. Perirenal fat tissue weight, and plasma TG, T-cho and leptin concentration was observed among these three groups. The plasma insulin concentration in dams fed the LFD was higher than that of the other two groups $(p<0.05)$.

Litter size in the groups receiving the LFD, the CTD and the HFD was $13.8 \pm 2.6,13.6 \pm 2.1$ and $11.3 \pm 1.5$, 
Table 4. Food and energy intake during the self-selection period by weaning pups of dams fed the LFD, the CTD and the HFD.

\begin{tabular}{|c|c|c|c|}
\hline Group & LFD & CTD & HFD \\
\hline \multicolumn{4}{|c|}{ Pair 1 (two-choice diet of LFD and HFD) } \\
\hline \multicolumn{4}{|l|}{ Males } \\
\hline LFD intake $(\mathrm{g})$ & $51 \pm 4^{\mathrm{b}}$ & $109 \pm 11^{\mathrm{a}}$ & $15 \pm 6^{c}$ \\
\hline HFD intake $(\mathrm{g})$ & $240 \pm 31^{\mathrm{a}}$ & $167 \pm 14^{\mathrm{b}}$ & $239 \pm 24^{\mathrm{a}}$ \\
\hline HFD intake ratio (\%) & $82.5 \pm 9.3^{\mathrm{a}}$ & $61.5 \pm 10.9^{b}$ & $94.1 \pm 7.7^{\mathrm{a}}$ \\
\hline Energy intake (kcal) & $1,283 \pm 91$ & $1,149 \pm 73$ & $1,152 \pm 108$ \\
\hline \multicolumn{4}{|l|}{ Females } \\
\hline LFD intake $(\mathrm{g})$ & $43 \pm 5^{b}$ & $102 \pm 8^{a}$ & $7 \pm 3^{c}$ \\
\hline HFD intake (g) & $190 \pm 25^{\mathrm{a}}$ & $127 \pm 9^{b}$ & $214 \pm 22^{\mathrm{a}}$ \\
\hline HFD intake ratio (\%) & $81.6 \pm 9.9^{b}$ & $55.5 \pm 6.1^{\mathrm{a}}$ & $96.8 \pm 12.1^{\mathrm{c}}$ \\
\hline Energy intake (kcal) & $1,025 \pm 95$ & $942 \pm 51$ & $1,009 \pm 88$ \\
\hline \multicolumn{4}{|c|}{ Pair 2 (two-choice diet of LFD and HFDLE) } \\
\hline \multicolumn{4}{|c|}{ Males } \\
\hline LFD intake (g) & $155 \pm 19^{a}$ & $168 \pm 13^{\mathrm{a}}$ & $56 \pm 5^{\mathrm{b}}$ \\
\hline HFDLE intake (g) & $99 \pm 12^{\mathrm{a}}$ & $120 \pm 25^{\mathrm{a}}$ & $242 \pm 18^{b}$ \\
\hline HFDLE intake ratio (\%) & $39.0 \pm 11.2^{\mathrm{a}}$ & $41.8 \pm 9.0^{\mathrm{a}}$ & $81.3 \pm 8.4^{\mathrm{b}}$ \\
\hline Energy intake (kcal) & $889 \pm 66^{\mathrm{a}}$ & $1,008 \pm 105^{\mathrm{ab}}$ & $1,043 \pm 88^{b}$ \\
\hline \multicolumn{4}{|l|}{ Females } \\
\hline LFD intake (g) & $129 \pm 16^{\mathrm{a}}$ & $130 \pm 12^{\mathrm{a}}$ & $52 \pm 5^{b}$ \\
\hline HFDLE intake (g) & $91 \pm 7^{\mathrm{a}}$ & $113 \pm 15^{b}$ & $197 \pm 27^{c}$ \\
\hline HFDLE intake ratio (\%) & $41.4 \pm 8.0^{\mathrm{a}}$ & $46.6 \pm 10.2^{\mathrm{a}}$ & $79.3 \pm 12.1^{b}$ \\
\hline Energy intake (kcal) & $770 \pm 60$ & $851 \pm 49$ & $872 \pm 101$ \\
\hline
\end{tabular}

Values represent means \pm SD, $n=8$. Within each row, values not sharing a common superscript letter are significantly different at $p<0.05$. The pups were weaned on day 21 of age. Immediately after weaning, male and female pups of dams fed the LFD, the CTD and the HFD were divided into two groups, each. One male and female subgroup (Pair 1) for each group pups nursed by dams fed the LFD, the CTD or the HFD were placed on a self-selection regimen of the LFD and the HFD, for 3 wk. The other groups (Pair 2) were placed on a self-selection regimen of the LFD and the HFDLE, for 3 wk.

respectively. Within $24 \mathrm{~h}$ of birth, litters were weighed. The body weight of pups of dams fed the LFD, the CTD and the HFD was $7.0 \pm 0.4,6.5 \pm 0.6$ and $6.6 \pm 0.6 \mathrm{~g}$, respectively. Therefore, maternal diets did not affect litter size nor did they affect the birth weight of pups.

However, on day 21 after birth, the body weight of pups nursed by dams fed the LFD was significantly lower than that of pups nursed by dams fed the CTD and the HFD (Table 3$)(p<0.05)$. The perirenal fat tissue weight of pups nursed by dams fed the LFD was the lowest and that of pups nursed by dams fed the HFD was the highest among the three groups $(p<0.05)$. The plasma TG concentration of pups nursed by dams fed the LFD was the lowest and that of pups nursed by dams fed the HFD was the highest among three groups $(p<0.05)$. However, no significant difference in plasma T-cho concentration was observed among the three groups. The plasma insulin concentration of pups nursed by dams fed the LFD was higher than that of the other two groups $(p<0.05)$. The plasma leptin concentration of pups nursed by dams fed the LFD was the lowest and that of pups nursed by dams fed the HFD was the highest among three groups $(p<0.05)$.

Food and energy intakes during the self-selection period by weaning pups nursed by dams fed the LFD, the CTD and the HFD

No significant difference in growth was observed between male and female suckling pups. However, as it is known that the growth of male pups is significantly larger than that of female pups after weaning $(17,18)$, we showed data for male and female pups separately in Tables 4 and 5 and Figs. 1 and 2 .

After weaning, pups in Pair 1 were provided both the LFD and the HFD, placed in separate cups. In male and female pups, the LFD intake of the CTD group was the highest and that of the HFD group was the lowest among the three groups. The HFD intake of the CTD group was lower than that of the other two groups $(p<0.05)$ (Table 4). Therefore, in male and female pups, the HFD intake ratio of the CTD group was lower than that of the other two groups $(p<0.05)$. No significant difference in energy intake was observed among the three groups.

The HFD intake ratio of the LFD, the CTD and the HFD groups in Pair 1 is illustrated in Fig. 1. In male and female pups, no significant difference in the HFD intake ratio was observed among the three groups within the first week of the self-selection period. Although no significant difference in the ratio of the LFD and the HFD groups was observed during the self-selection period, that of the CTD group decreased after the second week $(p<0.05)$. Therefore, from the third week, the ratio of the CTD group was lower than that of the other two groups $(p<0.05)$. 
Table 5. Body and perirenal fat tissue weights, and plasma lipid and hormone concentrations in weaning pups fed the two-choice diet of the LFD and the HFD, or the LFD and the HFDLE for $3 \mathrm{wk}$.

\begin{tabular}{|c|c|c|c|}
\hline Group & LFD & CTD & HFD \\
\hline \multicolumn{4}{|c|}{ Pair 1 (two-choice diet of LFD and HFD) } \\
\hline \multicolumn{4}{|l|}{ Males } \\
\hline Body weight (g) & $208 \pm 14$ & $205 \pm 20$ & $215 \pm 26$ \\
\hline $\begin{array}{l}\text { Perirenal fat tissue weight } \\
\text { (g/100 g body weight })\end{array}$ & $0.662 \pm 0.105$ & $0.583 \pm 0.051$ & $0.747 \pm 0.159$ \\
\hline \multicolumn{4}{|l|}{ Plasma concentration } \\
\hline Triacylglycerol (mg/dL) & $95.5 \pm 9.1^{\mathrm{a}}$ & $72.3 \pm 13.7^{\mathrm{b}}$ & $89.2 \pm 20.2^{\mathrm{ab}}$ \\
\hline T-cholesterol (mg/dL) & $82.1 \pm 10.3$ & $74.7 \pm 6.8$ & $89.7 \pm 11.3$ \\
\hline Insulin $(\mathrm{ng} / \mathrm{mL})$ & $2.77 \pm 1.03$ & $3.06 \pm 0.88$ & $2.28 \pm 0.32$ \\
\hline Leptin $(\mathrm{ng} / \mathrm{mL})$ & $3.99 \pm 1.01^{\mathrm{a}}$ & $2.38 \pm 0.24^{\mathrm{b}}$ & $4.15 \pm 1.93^{\mathrm{a}}$ \\
\hline \multicolumn{4}{|l|}{ Females } \\
\hline Body weight (g) & $181 \pm 17$ & $176 \pm 15$ & $183 \pm 24$ \\
\hline $\begin{array}{l}\text { Perirenal fat tissue weight } \\
\text { ( } \mathrm{g} / 100 \mathrm{~g} \text { body weight })\end{array}$ & $0.552 \pm 0.072$ & $0.438 \pm 0.115$ & $0.589 \pm 0.149$ \\
\hline \multicolumn{4}{|l|}{ Plasma concentration } \\
\hline Triacylglycerol (mg/dL) & $81.6 \pm 7.9$ & $66.2 \pm 10.8$ & $78.5 \pm 14.1$ \\
\hline T-cholesterol (mg/dL) & $78.2 \pm 6.8$ & $67.9 \pm 7.3$ & $78.8 \pm 15.4$ \\
\hline Insulin $(\mathrm{ng} / \mathrm{mL})$ & $2.54 \pm 0.62$ & $2.61 \pm 1.07$ & $2.09 \pm 0.71$ \\
\hline Leptin (ng/mL) & $3.05 \pm 0.68$ & $2.76 \pm 1.14$ & $3.52 \pm 0.49$ \\
\hline \multicolumn{4}{|c|}{ Pair 2 (two-choice diet of LFD and HFDLE) } \\
\hline \multicolumn{4}{|c|}{ Males } \\
\hline Body weight (g) & $172 \pm 12^{\mathrm{a}}$ & $199 \pm 11^{b}$ & $207 \pm 28^{b}$ \\
\hline $\begin{array}{l}\text { Perirenal fat tissue weight } \\
\text { ( } \mathrm{g} / 100 \mathrm{~g} \text { body weight })\end{array}$ & $0.529 \pm 0.091^{\mathrm{a}}$ & $0.538 \pm 0.121^{\mathrm{a}}$ & $0.708 \pm 0.069^{\mathrm{b}}$ \\
\hline \multicolumn{4}{|l|}{ Plasma concentration } \\
\hline Triacylglycerol (mg/dL) & $69.8 \pm 10.3$ & $73.6 \pm 7.9$ & $91.4 \pm 16.7$ \\
\hline T-cholesterol (mg/dL) & $67.2 \pm 6.8$ & $66.4 \pm 9.2$ & $77.4 \pm 5.9$ \\
\hline Insulin $(\mathrm{ng} / \mathrm{mL})$ & $2.92 \pm 1.26$ & $3.15 \pm 0.46$ & $2.36 \pm 0.85$ \\
\hline Leptin $(\mathrm{ng} / \mathrm{mL})$ & $2.62 \pm 1.35^{\mathrm{ab}}$ & $2.29 \pm 0.38^{\mathrm{a}}$ & $4.26 \pm 1.62^{\mathrm{b}}$ \\
\hline \multicolumn{4}{|l|}{ Females } \\
\hline Body weight (g) & $146 \pm 10^{\mathrm{a}}$ & $167 \pm 11^{b}$ & $178 \pm 18^{\mathrm{b}}$ \\
\hline $\begin{array}{l}\text { Perirenal fat tissue weight } \\
\text { (g/100 g body weight })\end{array}$ & $0.428 \pm 0.066$ & $0.430 \pm 0.091$ & $0.578 \pm 0.127$ \\
\hline \multicolumn{4}{|l|}{ Plasma concentration } \\
\hline Triacylglycerol (mg/dL) & $67.1 \pm 5.8$ & $65.4 \pm 6.9$ & $80.6 \pm 11.7$ \\
\hline T-cholesterol (mg/dL) & $66.5 \pm 7.4$ & $65.3 \pm 8.0$ & $77.9 \pm 9.5$ \\
\hline Insulin $(\mathrm{ng} / \mathrm{mL})$ & $2.73 \pm 0.81$ & $2.58 \pm 0.77$ & $1.98 \pm 0.57$ \\
\hline Leptin (ng/mL) & $2.44 \pm 0.54$ & $2.67 \pm 0.83$ & $3.26 \pm 1.14$ \\
\hline
\end{tabular}

Values represent means \pm SD, $n=8$. Within each row, values not sharing a common superscript letter are significantly different at $p<0.05$. The pups were weaned on day 21 of age. Immediately after weaning, male and female pups of dams fed the LFD, the CTD and the HFD were divided into two groups each. One male and female subgroup (Pair 1) for each of pups nursed by dams fed the LFD, the CTD and the HFD were placed on a self-selection regimen of the LFD and the HFD. The other groups (Pair 2) were placed on a self-selection regimen of the LFD and the HFDLE.

After weaning, pups in Pair 2 were provided both the LFD and the HFDLE, placed in separate cups. In male and female pups, the LFD intake of the HFD group was lower than that of the other two groups $(p<0.05)$ (Table 4). Although in male pups, the HFDLE intake of the HFD group was higher than that of the other two groups, in female pups, the HFDLE intake of the LFD group was the lowest and that of the HFD group was the highest among the three groups $(p<0.05)$. In male and female pups, the HFDLE intake ratio of the HFD group was higher than that of the other two groups $(p<0.05)$. In male pups, the energy intake of the LFD group was the lowest and that of the HFD group was the highest among the three groups. In female pups, no significant difference in energy intake was observed among the three groups.

The HFDLE intake ratio of the three groups in Pair 2 is illustrated in Fig. 2. In male and female pups, no significant difference in the HFDLE intake ratio was observed among the three groups within the first week of the self-selection period. Although no significant difference in the ratio of the HFD groups was observed during the self-selection period that of the LFD and the CTD groups decreased after the second week $(p<0.05)$. 

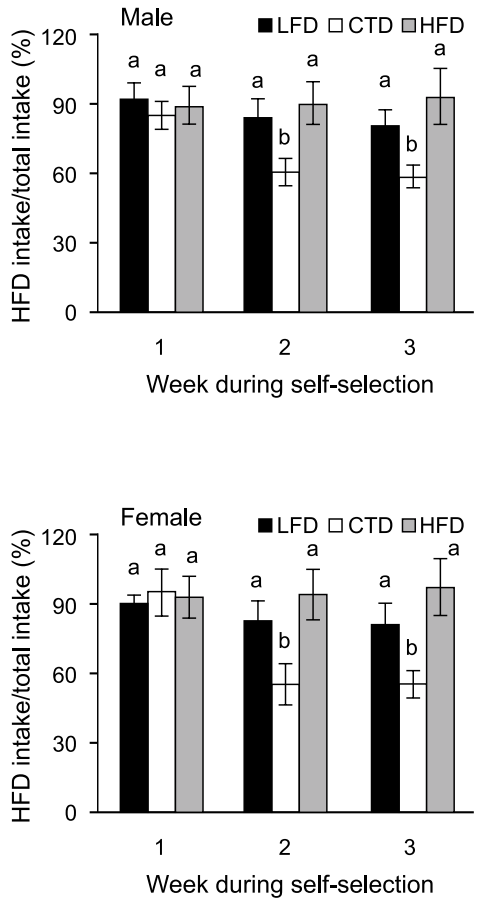

Fig. 1. The ratio of the HFD intake to the total diet intake by weaned male and female pups of dams fed the LFD, CTD and HFD when they were placed on a selfselection regimen with a two-choice diet program of the HFD and the LFD. Values are mean \pm SD. Values not sharing a common letter are significantly different at $p<0.05$.

Therefore, after the second week, the ratio of the HFD group was higher than that of the other two groups $(p<0.05)$.

Body and perirenal fat tissue weights, and plasma lipid and hormone concentrations in weaning pups fed the two-choice diet of the LFD and the HFD, or the LFD and the HFDLE for $3 w k$

In male and female pups of Pair 1, no significant difference in body and perirenal fat tissue weights was observed among the three groups. Although in male pups, the plasma TG concentration of the LFD group was the highest and that of the CTD was the lowest $(p<0.05)$, in female pups, no significant difference in the concentration was observed among the three groups. In male and female pups, no significant difference in T-cho or insulin concentrations was observed among the three groups. Although in male pups, the plasma leptin concentration of the CTD group was lower than that of the other two groups $(p<0.05)$, in female pups, no significant difference in the concentration was observed among the three groups.

In male and female pups of Pair 2, body weight of the LFD group was lower than that of the other groups $(p<0.05)$. Although in male pups, perirenal fat tissue weight of the HFD group was higher than that of the other groups $(p<0.05)$, in female pups, no significant difference in the weight was observed among the three groups. No significant difference in plasma TG, T-cho or insulin concentration was observed among the three groups. Although in male pups, the plasma leptin con-
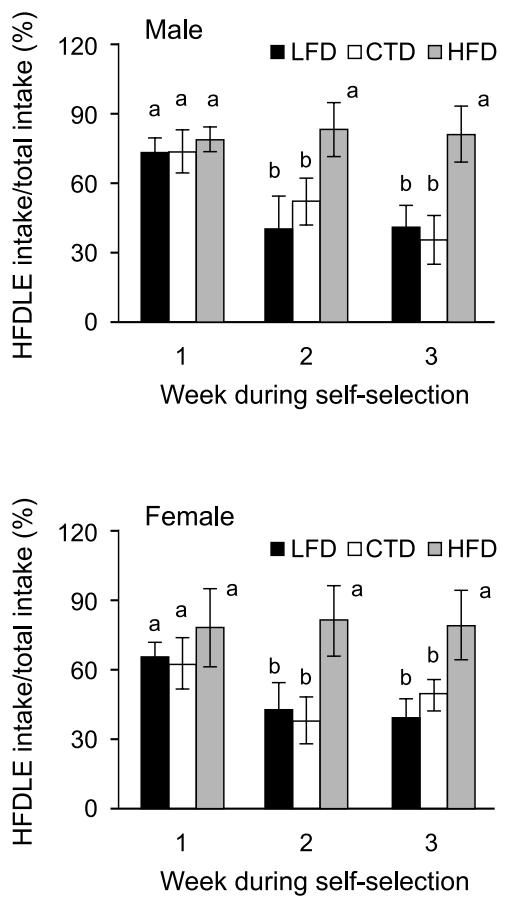

Fig. 2. The ratio of the HFDLE intake to the total diet intake by weaned male and female pups of dams fed the LFD, CTD and HFD when they were placed on a selfselection regimen with a two-choice diet program of the HFDLE and the LFD. Values are mean \pm SD. Values not sharing a common letter are significantly different at $p<0.05$.

centration of the HFD group was the highest and that of the CTD group was the lowest among the three groups $(p<0.05)$, in female pups, no significant difference in the concentration was observed among the three groups.

\section{DISCUSSION}

Although no significant difference in energy intake during pregnancy was observed among the three groups, the energy intake of dams fed the LFD during the nursing period was lower than that of dams fed the HFD. It is likely that dams fed the LFD containing lowfat and low-energy could not consume the necessary energy during the nursing period. However, at the end of lactation, no significant difference in body or perirenal fat tissue weights of dams was observed among these three groups. Instead, at the end of the suckling period, body or perirenal fat tissue weights of pups nursed by dams fed the LFD were lower than that of pups nursed by dams fed the HFD.

However, the plasma insulin concentration in dams fed the LFD containing a high level of carbohydrate was higher than that of the other groups. There are many reports that insulin affects fatty acid synthesis by altering the gene expression of acetyl-CoA carboxylase in the rate-limiting step of fatty acid synthesis (20-22) and the increase in quantities of lipogenic enzymes in the liver are induced by a high carbohydrate diet (2326). Therefore, it was assumed that the intake of the LFD increased the fatty acid synthesis in the liver. As 
the synthesized lipids in the liver were transferred to blood as VLDL, in this study, no significant difference in the plasma TG concentration was observed among the three groups.

Although maternal diets did not affect litter size nor birth weight of pups, at the end of lactation, the body weight of suckling pups nursed by dams fed the LFD was lower than that of the other groups. The same phenomenon was observed in our previous paper (18). We also reported in the previous paper that no clear difference in energy ratios (PFC ratio) in the stomach content of 8-d-old suckling pups was observed among the pups nursed by dams fed the LFD, the CTD or the HFD. Keen et al. reported that the $\mathrm{F}$ ratio in rat milk was about $70 \%$ and no clear change was observed in the PFC ratio in milk during the lactation period (27). Del Prado et al. also observed that the $\mathrm{F}$ ratios of milk from rats fed a LFD (25 g/ $\mathrm{kg}$ diet) and the HFD (200 g/kg diet) were about 74 and $76 \%$, respectively (28). Therefore, it was supposed that the body weight of suckling pups of dams fed the LFD was lower than that of the other groups due to the amount of milk consumed. The pups of dams fed the LFD consumed less milk than pups of the other groups.

Although the plasma TG concentration in suckling pups of dams fed the LFD was the lowest among the three groups, the plasma insulin concentration in pups of dams fed the LFD was higher than that of the other pup groups. One reason for this finding appeared to be that suckling pups were nibbling their dam's diet before weaning. Therefore, it was assumed that in suckling pups of dams fed the LFD, due to the consumption of the LFD containing high levels of carbohydrates, the plasma TG concentration was lower and the plasma insulin concentration was higher than that of the other groups.

In week 1 after weaning, three groups of male and female pups in Pair 1 were fed a large amount of the HFD (Fig. 1). It thus appeared that all pups fed high-fat milk during the suckling period self-selected a large amount of the HFD immediately after weaning. As the HFD intake ratios were about $90 \%$, F ratios were calculated to be about $39 \%$. Although no significant difference appeared in the $\mathrm{F}$ ratio of male and female pups nursed by dams fed the LFD and the HFD during the self-selection period, that of the CTD group decreased by about $29 \%$ after 2 wk. Jean et al. performed a study in which pregnant Wistar dams were fed a standard pregnancy and breeding diet during pregnancy and lactation, and after weaning their pups received threemacronutrient-choice diets placed in separate cups (14). The fat intake in the self-selecting pups fell for 3 wk after weaning, and reached a plateau from weeks 3 to 7 after weaning. Similarly, the F ratio of male and female pups nursed by dams fed the CTD in Pair 2 decreased from 33 to $20 \%$ (Fig. 2).

However, after weaning, both groups of male and female pups nursed by dams fed the HFD in Pair 1 and Pair 2 had a strong preference for the HFD and the HFDLE, respectively. One reason for this finding appeared to be that the pups were nibbling their dam's diet before they were weaned. Nibbling the diet containing large amount of lard might have affected the pups' dietary preferences after weaning.

The HFD intake ratio of the LFD group in Pair 1 did not decrease after weaning and in male and female pups, the ratio of pups nursed by dams fed the LFD was higher than that of pups nursed by dams fed the CTD. On the other hand, the HFDLE intake ratio of the LFD group in Pair 2 decreased after weaning and in male and female pups, no significant difference in the ratio was observed between the pups nursed by dams fed the LFD and the CTD. In Pair 1, the body weight gain ratio [body weight gain during the self-selection period (g)/ body weight at weaning $(\mathrm{g})$ ] during the self-selection period of male pups nursed by dams fed the LFD, the CTD and the HFD was 4.0, 3.5 and 3.4, respectively, and that of female pups nursed by dams fed the LFD, the CTD and the HFD was 3.5, 3.0 and 2.9, respectively. Therefore, the body weight gain ratio of male and female pups nursed by dams fed the LFD was higher than that of the other groups and the body weight of male and female pups nursed by dams fed the LFD caught up with the other groups by the self-selection of the LFD and the HFD. In Pair 2, the body weight gain ratio during the self-selection period of male pups nursed by dams fed the LFD, the CTD and the HFD was 3.3, 3.4 and 3.3, respectively, and that of female pups nursed by dams fed the LFD, the CTD and the HFD was 2.8, 2.9 and 2.8, respectively. Therefore, in male and female pups, no significant difference in the body weight gain ratio was observed among the three groups. At the end of the self-selection period, the body weight of male and female pups nursed by dams fed the LFD was lower than that of the other groups. One of the reasons for this finding was likely that, as pups of the LFD group needed a high energy density diet in order to increase their body weight, the pups of the LFD group spontaneously consumed a larger amount of the HFD than pups of the CTD group. Therefore, although the pups nursed by dams fed the LFD during pregnancy and lactation showed a strong preference for the HFD, they did not show preference for the HFDLE after weaning.

In male and female pups in Pair 1 , the $\mathrm{F}$ ratio of the LFD, CTD and the HFD group after the second week of the self-selection period was calculated from the HFD intake ratio to be $37.4,29.5$ and $39.0 \%$, respectively. Similarly, in male and female pups in Pair 2, the F ratio of the LFD, CTD and the HFD group was calculated from the HFDLE intake ratio to be 20.8, 22.3 and $32.7 \%$, respectively. All these F ratios were higher than that of the CTD $(17.1 \%)$. The plasma insulin concentration of dams fed the LFD and of their pups who nibbled their dam's diet was higher than that of the other groups. However, at the end of the self-selection period, no significant difference in plasma insulin concentration was observed among the three groups. Therefore, the selfselection diet appeared to prevent the increase in plasma insulin observed in dams and pups fed the LFD. It was assumed that the pattern of dietary selection of 
pups after weaning was related to the reduced plasma insulin concentration. It seems to be generally accepted that hyperinsulinemia does develop in rats fed high-carbohydrate diets while the basal plasma glucose level does not increase, mainly due to a loss of sensitivity to insulin with age together with high-carbohydrate ingestion (29). Although glucose homeostasis may remain normal, insulin concentrations tend to increase with age. Namely, insulin resistance in peripheral tissues increases with age. Berthelier et al. demonstrated that a decrease in insulin sensitivity could take place early in development (30). In this study, at the end of the suckling period, the average plasma insulin concentration in pups nursed by dams fed the LFD was already higher than that in pups nursed by dams fed the CTD and the HFD. Therefore, as pups become older, a highcarbohydrate diet may lead to insulin resistance. In conclusion, the choice of a high-ratio of the HFD in pups nursed by dams fed the LFD could be related to improved insulin sensitivity and might prevent the onset of insulin resistance in later life. The LFD group needed a high energy density diet to increase their body weight to levels approaching the other groups. Additional studies are required to validate this supposition and to describe the precise mechanism involved in this differentiation.

\section{REFERENCES}

1) Regnault N, Botton J, Forhan A, Hankard R, Thiebaugeorges O, Hillier TA, Kaminski M, Heude B, Charles MA. 2010. Determination of early ponderal and statural growth in full-term infants in the EDEN motherchild cohort study. Am J Clin Nutr 92: 594-602.

2) Herrera E. 2002. Implications of dietary fatty acids during pregnancy on placental, fetal and post natal development (a review). Placenta 23: S9-S19.

3) Campfield L, Smith F, Gulsez Y, Devos R, Burm P. 1995. Evidence for a peripheral signal linking adiposity and central nervous networks. Science 269: 546-549.

4) Schwartz MW, Woods CS, Porte D, Seeley RJ, Baskin DG. 2000. Central nervous system of food intake. Nature 404: 661-671.

5) Little TJ, Horowitz M, Feinle-Bisser C. 2007. Modulation by high-fat diets of gastrointestinal function and hormones associated with the regulation of energy intake: implications for the pathophysiology of obesity. Am J Clin Nutr 86: 531-541.

6) Baskin D, Breininger J, Schwarts M. 1999. Leptin receptor mRNA identifies a subpopulation of neuropeptide $\mathrm{Y}$ neurons activated by fasting in rat hypothalamus. Diabetes 48: 824-833.

7) Fraze E, Chiu M, Chen Y. 1987. Age related changes in postprandial plasma glucose, insulin and FFA concentrations in non-diabetic individuals. J Am Geriatric Soc 35: 224-228.

8) Gommers A, De Gasparo M. 1972. Variation of insulinemia in relation to age in the untreated male rats. Gerontologia 18: 176-184.

9) Friedman JM, Halaas JL. 1998. Leptin and the regulation of body weight in mammals. Nature 395: 763770.

10) Vickers MH, Ikenasio BA, Breier BH. 2001. IGF-I treatment reduces hyperphagia, obesity and hypertention in metabolic disorders induced by fetal programming. Endocrinology 142: 3964-3973.

11) Vickers MH, Gluckman PD, Coveny AH, Hofman PL, Cutfield WS, Gertler A, Breier BH, Harris M. 2005. Neonatal leptin treatment reverses developmental programming. Endocrinology 146: 4211-4216.

12) Trottier G, Koski KG, Brun T, Toufexis DJ, Richard D, Walker CD. 1998. Increased fat intake during lactation modified hypothalamic-pituitary-adrenal responsiveness in developing rat pups: a possible role for leptin. Endocrinology 139: 3704-3711.

13) Cha MC, Jones PJH. 1998. Dietary fat type and energy restriction interactivity influence plasma leptin concentration in rats. J Lipid Res 39: 1655-1660.

14) Jean C, Fromentin G, Tome D, Laure-Achagiotis C. 2002. Wistar rats allowed to self-select macronutrients from weaning to maturity choose a high-lipid diet. Physiol Behav 76: 65-73.

15) Bellinger L, Lilley C, Langley-Evans SC. 2004. Prenatal exposure to a maternal low-protein diet program. A preference for high-fat foods in the young adult rat. $\mathrm{Br} J$ Nutr 92: 513-520.

16) Saito M, Ishii T, Takewaki T, Nishimura M. 2005. Preference for safflower oil in rats exposed to a cold environment under free-feeding conditions. J Vet Med Sci 67: 653-658.

17) Nakashima Y. 2007. Effect of dams' dietary fat type during pregnancy and lactation on the preferential fat intake in their pups after weaning. J Jpn Soc Nutr Food Sci 60: 241-247 (in Japasese).

18) Nakashima Y, Tsukita Y, Yokoyama M. 2008. Preferential fat intake of pups nursed by dams fed low fat diet during pregnancy and lactation is higher than that of pups nursed by dams fed control diet and high fat diet. $J$ Nutr Sci Vitaminol 54: 215-222.

19) American Institute of Nutrition. 1993. AIN-93G purified diets for laboratory rodents: final reports of the American Institute of Nutrition ad hoc writing committee on the reformation of the AIN-73A rodent diet. J Nutr 123: 1939-1951.

20) Pape ME, Lopez-Casillas F, Kim K-H. 1988. Physiological regulation of acetyl-CoA carboxylase gene expression: Effect of diet, diabetes and lactation on acetyl-CoA carboxylase mRNA. Arch Biochem Biophys 257: 63-68.

21) Katsurada A, Iritani N, Fukuda H, Matsumura Y, Nishimoto N, Noguchi T, Tanaka T. 1991. Effects of nutrients and hormones on transcriptional and post-transcriptional regulation of acetyl-CoA carboxylase in rat liver. Eur J Biochem 190: 435-441.

22) Dai ZH, Xing YZ, Boney CM. 1994. Human insulin-like growth factor-binding protein-1 (hIGFBP-1) in transgenic mice: Characterization and insights into the regulation of IGFBP-1 expression. Endocrinology 135: 13161327.

23) Iritani N. 1992. A review. Nutritional and hormonal regulation of lipogenic enzyme expression in rat liver. Eur J Biochem 205: 433-442.

24) Prostko CR, Frits RS, Kletzien R. 1989. Nutritional regulation of hepatic glucose-6-phosphate dehydrogenase. Biochem J 258: 295-299.

25) Towle HC, Kaytor EN, Shih H-M. 1997. Regulation of the expression of lipogenic enzyme genes by carbohydrate. Annu Rev Nutr 17: 405-433.

26) Fukuda H, Katsurada A, Iritani N. 1992. Effect of nutrients and hormones on gene expression of ATP citrate- 
lyase in rat liver. Eur J Biochem 209: 217-222.

27) Keen CL, Lonnerdal B, Clegg M, Hurley LS. 1981. Developmental change in composition of rat milk: Trace elements, mineral protein, carbohydrate and fat. J Nutr 111: 226-230.

28) Del Prado M, Delgado G, Villalpando S. 1997. Maternal lipid intake during pregnancy and lactation alters milk composition and production and litter growth in rats. $J$ Nutr 127: 458-462.
29) Bezerra RMN, Ueno M, Silva MS, Tavares DQ, Cavalho CRO, Saad MJA. 2000. A high fructose diet affects the early steps of insulin action in muscle or liver of rats. $J$ Nutr 130: 1531-1535.

30) Berthelier C, Kergoat M, Portha B. 1997. Lack of deterioration of insulin action with aging in the GK rats: a contrasted adaptation as compared with non-diabetic rats. Metabolism 46: 890-896. 